\title{
Parasites, ghosts and mutualists: a relational geography of microbes for Global Health
}

\section{Homo microbis}

Recent developments in gene sequencing have helped identify the vast diversity of microbial life in, on and around the human body. Scientists interested in this microbiome offer a figure of the human as Homo microbis (Helmreich, 2015), comprised of bacteria, viruses, fungi, archaea and even a few animals invisible to the naked eye. The composition and dynamics of the human microbiome are increasingly implicated in discussions of human health (Relman, 2015). We are learning more about the causes of infectious diseases, but we also increasingly hear about beneficial microbes and the consequences of their decline or absence.

'Missing microbes' (Blaser, 2014) have been associated with a range of metabolic, immunological, and mental health conditions - including allergy, obesity, inflammatory bowel disease and depression. These 'epidemics of absence' (Velasquez-Manoff, 2012) have been tied to situations of microbial imbalance or 'dysbiosis' (Logan et al., 2016). While causal links are not yet clear, and these claims are contested, a widespread reappraisal is underway in modern medicine of the salutary potential of the microbiome and the therapeutic use of microbes. ${ }^{1}$

This medical microbiology of missing and beneficial microbes departs from the germ theory of disease, in which a specific malady is linked to a specific microbe. Instead it is founded on an ecological or configurational model. Here no microbe is inherently pathogenic (Méthot and Alizon, 2014): context and relations matter. Disease is presented as the emergent outcome of complex, spatio-temporal interactions between the host immune system and microbiota and the external microbial environment (Hinchliffe et al., 2016).

These developments in microbiology have some profound implications for the geography of health and disease. While there is a long history of relational and ecological work on health in geography and anthropology, this has largely been premised on a negative understanding of microbes. Spatial patterns of microbial presence and abundance have been taken as an index of socio-economic development: 
fewer microbes = better places. This 'antimicrobial' geography informed the history of public health and is also true for Global Health, the 'area for study, research, and practice that places a priority on improving health and achieving equity in health for all people worldwide' (Koplan et al 2009, 1995. See also Brown and Moon, 2012; Herrick and Reubi, 2017). Global Health describes a diverse range of programmes. But they are united by an antimicrobial concern with the control and/or eradication of infectious diseases. There is currently little room in geography or in Global Health for understanding health and disease as configured by missing or beneficial microbes.

To address this gap, this paper develops a relational geography of microbes and the diseases of microbial dysbiosis. To do so it builds from recent relational approaches at the interface of more-than-human geography and political ecology. These examine health and disease as multispecies conditions configured by specific socio-ecological 'situations' (Hinchliffe et al., 2016). The concept of a disease situation foregrounds the political and ecological relations that shape the 'intensities' of human-animalmicrobial interaction that might lead to pathogenesis - or the emergence of disease.

The analysis in this paper develops the prevalent concerns in this literature with infectious diseases associated with microbial excess. Here microbes are parasites, benefiting at the expense of their hosts. It then turns to disease situations marked by missing microbes. Here microbes figure as ghosts whose absent presence causes dysbiosis. The paper then attends to disease situations that are addressed through proactive microbial introduction and management. Here microbes become mutualists performing relations with the host of reciprocal benefit. The human-microbial relations captured by the three figures of the parasite, ghost and mutualist are those of upmost concern to medical scientists engaging with the microbiome. The three labels that describe these relations are taken from the microbiology literature.

In identifying these three figures and tracing their political ecologies the paper aims to offer geographers a more expansive conception of human microbial relations and the forms of 'microbiopolitics' (Paxson, 2008) that might underpin contemporary approaches to Global Health. It supplements long-standing concerns with antimicrobial or 'Pasteurian' approaches to healthcare, that are focused on the microbial parasite, with an attention to probiotic or 'post-Pasteurian' (Paxson, 2008) 
alternatives. These seek to manage and modulate human infection intensities to channel the mutualistic potential of microbes.

\section{Hookworms}

The analysis in this paper focuses on human relations with hookworms (Necator americanus, Figure 1). Hookworms are helminths and comprise one of the few animal components of the human microbiome. They are microscopic in their larval stage, during which they live outside of the human body. Hookworms are biologically very different to the bacteria that have become the main foci of microbiome research. Some microbiologists might even contest their inclusion in the microbiome. But, as I hope to show in this analysis, the bifurcated geographies of hookworm disease situations, and an emerging understanding of the worms' role in configuring the human microbiome, make them ideal subjects for a relational geography of microbes.

Hookworms live in our guts and feed on our blood. They reproduce by laying their eggs in our faeces. Larvae hatch in warm, moist, shitty soil and seek to re-enter human bodies through the skin. Subsequent stages in the life cycle (Figure 2) see the larvae migrate to the heart, from where they eat their way into the lung. They are coughed up and swallowed, returning to the gut. Hookworms co-evolved with people and each worm can live in the host for several years. 'Colonies' tend to develop fairly slowly and a modest 'wormload' can be tolerated without symptoms.

Figure 1 here

Figure 2 here

Figure 3 here

Hookworms can become pathogenic in different socio-ecological situations. Excessive hookworm infection causes significant morbidity to more than 500 million people in rural areas of low-income countries (CDC, 2016) (Figure 3). Hookworms are the second most significant parasitic infection after malaria (Hotez, 2013), and are the subject of Global Health initiatives to 'deworm the world' (Evidence Action, 2016). Hookworms were eradicated from North America and Europe at the start of the twentieth century through the development of antimicrobial drugs and improvements in sanitation (Ettling, 2013). The absence of hookworms has been 
implicated in the rise of dysbiosis. The demise of these 'old friends' (Rook 2009a) is understood to imbalance the immune system, turning it against the self and generating a range of autoimmune, allergic and inflammatory disease. Clinical trials are underway to test the potential of helminthic therapy (Wammes et al 2014). These trials have been overtaken by the 'hookworm underground' (Velasquez-Manoff, 2012): an international network of patients who breed worms at home and distribute them through the Internet. There is growing industry interest in replicating hookworm's immunosuppression in pill form (Ditgen et al 2014).

This seeming spatial paradox, of concurrent programmes to 'deworm' and 'reworm' the world, provides a compelling rationale for a relational geography of microbes and of dysbiosis. Hookworms are not inherently pathological. They become so because of shifts in the intensities of their socio-ecological relations. These shifts give rise to disease situations marked by both excessive presence and by recent absence. Too many or too few hookworms can cause dysbiosis. The paper details three contrasting human-hookworm relations, which are described by the political-ecological figures of the parasite, ghost and mutualist that were introduced above. It critically examines their multispecies character, and prevalent political-economic and microbiopolitical relations. The conclusion reflects on the implications of this analysis for the geographies of health and disease, and for the practices of Global Health. It assesses the contributions the figure of Homo microbis could make to developing more-thanhuman approaches to the geographies of health. It suggests a need to recognise multiple forms of microbial humans by mapping the patchiness of situations in which people can live well with and without hookworms. It links these geographies to prevalent patterns of inequality. It advocates for forms of healthcare better calibrated to the pathological potential of microbial excess and absence, and the mutualistic possibilities of living with microbes. These alternatives challenge the antimicrobial orthodoxy, essentialist models of the microbial pathogen, and the magic bullet solutions to disease ascendant in Global Health.

\section{Relational geographies of microbes}

Medical geographers and anthropologists have long been concerned with microbes in their studies of disease ecology (Mayer, 2010). This work resonates (in often underexplored ways) with more recent ethnographic research on health in more-than- 
human and multispecies studies (for a review see Nading, 2013). While these health literatures have yet to engage explicitly with the ecological ontologies of the microbiome, attention has been paid to exchanges between a wide range of viruses, bacteria and animals and human immune systems across a growing diversity of interspecies contact zones (e.g. Greenhough, 2012; Lowe, 2010; Bull, 2016; Beisel and Boëte, 2013). We can situate this multispecies turn within a wider shift towards relational understandings of disease in medicine and the social sciences (Anderson and Mackay, 2014).

Steve Hinchliffe and his co-authors $(2013 ; 2016)$ develop this work in their analysis of the geographies of biosecurity. They take issue with conventional 'Cartesian' mappings of disease as the outcome of universally pathogenic microbes crossing borders and infecting discrete territories. They note the importance of the extensive networks of globalisation in enacting and distributing 'socio-technical diseases' (see also Ali and Keil, 2011), but suggest that it is more informative to think of disease in terms of topologies of intensive relations. In their reading, topology refers to the complex spatio-temporal relations and intra-actions (after Karen Barad) that configure the 'intensities' of any socio-ecological situation. Bodies become ecologies entangled and enfolded within a geography of more or less pathogenic landscapes. These are marked by potential disease 'tipping points' (2013: 538). Here infectious disease does not come from an outside, but is 'ecosyndemic' (Singer, 2010): immanent from particular political ecological 'situations' whose shifting microbiologies create conditions of dysbiosis. Pathogenicity, they argue, is best conceived 'as a process, rather than a fixed object' (Hinchliffe et al., 2016: 25).

Work in this vein has tended to focus on the topologies of viral 'hotspots' (Brown and Kelly, 2014) 'clouds' (Lowe, 2010) and 'epidemic space' (Loon, 2005). A common concern lies with the intensified socio-ecological relations of contemporary agriculture, urbanization, and globalization, which are understood to generate 'blowback' (Wallace and Wallace, 2015), or the excessive presence of undesired microbes (Shukin, 2009; Porter, 2013; Wallace, 2009). Here microbial dysbiosis takes the form of 'crowd infections' (Wolfe et al., 2007) and emergent infectious and zoonotic disease. To date, there has been little work exploring the topologies of dysbiotic situations generated by microbial absence, or of the proactive efforts to tip 
bodily ecologies out of dysbiotic relations that we will encounter in the hookworm story. Indeed, there has been remarkably little research in geography or anthropology on allergy and the inflammatory and autoimmune diseases that are currently being associated with missing microbes (though see Mitman, 2008).

The critical impulse that shapes this relational, microbial turn is inspired by theories of the biopolitics of immunity, as well as more established concerns with political economy. For example, Hinchliffe and his co-authors (2016) are critical of the security practices - or what they term 'disease diagrams' - of modern intensive agriculture and associated programmes for One Health (Hinchliffe 2015). These, they argue, are premised on the separation and purification of animal bodies and ecologies and the denigration of vernacular and non-Western forms of expertise. They suggest that these generate 'autoimmune' tendencies, in which bodily (and by extension social) ecologies tip into a disease state when the immune system turns again itself in the absence of a co-evolved antagonist (Hinchliffe and Ward, 2014. See also Mutsaers, 2015; Brown and Nettleton, 2017).

Drawing on the writings of Roberto Esposito and Jacques Derrida, they illustrate more communitarian approaches to 'immunology management' on the farm (Hinchliffe and Ward, 2014). These are premised on the affirmative potential of encounters with social and microbial difference (in this case pig shit and the vernacular knowledge of the farmers who make it available. See also Law and Mol, 2008). They suggest that this strategic 'mucking up' enables tolerance, hospitality and mutual flourishing. We can find resonances of these communitarian approaches to immunology management in the shift from Pasteurian to 'post-Pasteurian' forms of 'microbiopolitics' that Heather Paxson $(2008$; 2014) has identified in her work on raw milk cheese production in North America. Post-Pasteurian approaches do not reject Pasteurisation, but involve more targeted means of managing microbial life, encouraging or living with some microbes to secure desired systemic properties. There is a nascent interest here in finding ethical means - however 'awkward' (Ginn et al., 2014) - of living well with microbes and their insect vectors.

These relational understanding of pathogenicity could be better linked to established writings in anthropology and political ecology on the structural violence and 
'pathologies of power' (Farmer, 2004) associated with colonial and capitalist forms of public health and biomedicine. There are important differences between work in this older, Marxist tradition and the new relational approaches (for discussion see Brown and Kelly, 2014; Guthman and Mansfield, 2013; Braun 2015). There is scope for a more systematic synthesis than can be offered here, but for the purposes of the analysis that follows I will identify one common concern and point of conceptual convergence. Hinchliffe et al (2016) give a 'topological twist' to established approaches to political economy in their analysis of campylobacter as a 'just-in-time' disease. In working viral agencies into theories of capitalism, they link the intensification of agriculture and its endemic dysbiosis to post-Fordist relations of labour precarity, commercial pressure and regulatory inefficacy. Their argument is that we can only understand the pathological intensification of human-microbial relations by tracing the globalising logics, practices and assemblages of contemporary capitalism. In the analysis that follows, I develop this conceptual framework by attending to the pathologies of power associated with the parasites of plantation capitalism, the inequalities amongst those facing microbial absence, and the emerging political ecologies of microbial reintroduction.

\section{Human-hookworm relations}

This account is structured to explore three types of human-hookworm relation, which are described by the ecological figures of the: parasite, ghost and mutualist. This analysis is informed by a close reading of scientific literatures on hookworms and interviews with a range of clinical practitioners and patients engaged with de- and reworming. It is not exhaustive of human-hookworm relations past, present, or hypothetical. Instead it offers a heuristic for developing a relational geography of microbes.

\section{Parasite}

Parasite is a polysemous word. Recent work in the social sciences (oft inspired by Serres, 2007) has developed transgressive, or even affirmative, figures of the parasite (Lezaun, 2011; Bull, 2016; Kelly, 2012). I touch on these in the discussion of other relational figures below. But in the interests of specificity, I take a rather narrow and negative biological definition of a parasite as: 'an organism that obtains nutrients at 
the expense of the host organism, which it may directly or indirectly harm' (OED, 2016).

Mortality as a direct result of 'hookworm disease' (Necatoriasis) is rare. But hookworms can become parasitic and thus pathogenic in particular politicalecological situations. Necatoriasis hotspots are characterised by high and protracted levels of infection intensity, where bare skin frequently comes into contact with the soil and a dysbiotic worm colony accumulates. High wormloads lead to protein deficiency and anaemia. They can affect cognitive function and development, especially amongst children (Brooker et al., 2004). We can find examples of such relations in critical histories of public health. These illustrate how the politicalecological intensities of colonial capitalism created the perfect conditions for hookworms to become parasitic. Steven Palmer argues that:

Hookworm disease was a sickness of ecological, economic, and cultural displacement and recombination; its virulent appearance along these teeming trenchworks of modernity went hand in hand with the increasing density and speed of the globe's road, rail, and ocean connections. A close relative of nineteenth-century capital, the hookworm parasite thrived in heated frontier regions where vulnerable bodies were amassed for hard labor, and it became potent through accumulation $(2009,679)$

Colonial mines, tunnels, railroad beds, and plantations (in India, Africa and the Americas) were ideal 'hotspots' (Brown and Kelly, 2014) for the genesis of hookworm disease, as were the settlements of indigenous peoples forcibly confined to reserves (e.g. in Australia). Hotspots were comprised of rapidly growing concentrations of displaced and poorly nourished people, suffering from high levels of reinfection as a result of bad sanitation and suitable soil (Couacaud, 2014).

Palmer suggests that in the $19^{\text {th }}$ century hookworms were 'simmering among rural peoples around the world'. They 'boiled over' because of the 'intense ecosocial disruptions' $(2009,708)$ of world capitalist expansion. The amplified intensities of these situations 'tipped' hookworms over a threshold, shifting them from a microbial old friend (more below) to a parasitic 'crowd infection'. Necatoriasis briefly became 


\section{Transactions of the Institute of British Geographers}

an 'industrial epidemic' (Jahiel and Babor, 2007) - a pre-Fordist precursor to the contemporary 'just-in-time’ diseases we encountered above. As various authors have argued, the 'macroparasitic' (i.e. asymmetrical and exploitative) character of plantation colonial capitalism exacerbated the 'microparasitic' depredations of the hookworm (see Brown, 1987).

During the early $20^{\text {th }}$ century hookworms became known as the 'germ of laziness' because of their effects on labour productivity (Ettling, 2013; Anderson, 2006). Subsequent scientific research and public health programmes (largely funded by the Rockefeller Foundation) sought to modulate infection intensities to control necatoriasis (Palmer, 2010; Farley, 2003). In the South of the USA, sanitation, footwear, drugs and education disentangled agricultural workers from the vectors for infection. Many people left hookworm hotspots for cities, and gradual improvements in nutrition helped boost host tolerance. Worms and other microbes were killed off in large numbers. Such programmes for hookworm control have all the hallmarks of the modern, antibiotic modes of microbiopolitics documented by Latour (1988) and other, more celebratory, historians of public health (e.g Farley, 2003). They involve systematic efforts to lock down and rationalise the circulation of microbial life, separating human bodies from the environment and purifying them of their component microbes.

The application of such antibiotic approaches is globally patchy and the biogeography of hookworm prevalence and infection intensity conforms to familiar maps of uneven development - to the extent that public health experts have devised a 'worm index' of human development (Hotez and Herricks, 2015). Some helminth infections are still common amongst minority populations living in poverty in North America and the EU (Hotez, 2009). But hookworms are now extinct in the 'wild' in these regions and their prevalence and infection intensity are on the wane across much of the urban Global South (Pullan and Brooker, 2012).

Parasitic relations with hookworms persist amidst rural populations in low-income countries, especially in Africa and South Asia. Highest infection intensities are often amongst children (Hotez et al., 2005). Sanitation projects have fallen out of favour as strategies for hookworm control and World Health Organisation attention and Gates 
Foundation funding is now focused on the regular distribution of deworming drugs to schoolchildren (WHO, 2016). The efficacy of school based deworming is fiercely contested (Evans, 2015), especially in areas with poor sanitation and high reinfection risk. Hookworms have also developed antimicrobial resistance and there has been limited investment in new drugs, as more affluent Northern markets have shrunk (Hotez et al., 2013).

This brief, topological analysis of hookworms-becoming-parasitical on crossing a threshold, suggests that necatoriasis is not necessary a disease of under-development resulting from the spread of a specific pathogen. Hookworms are not inherently pathological. They can be endemic and asymptomatic, but become pathogenic because of an increased intensity of exploitative, unequal or abandoned socioecological relations. In these situations, pathology is indexed to excessive presence and bodily dysbiosis is the outcome of the crossing of a disease threshold. Historians link the amplification of infection intensities to the pathologies of power associated with colonial capitalism, but they also caution against reading off hookworm disease as a universal outcome of systemic structural violence. The materialities of coinfection, host genetics and epigenetics, soil type, working conditions, defecation practices and sanitation investments all shape the differential emergence of infection intensities (Couacaud, 2014).

\section{Ghost}

A growing body of immunological theory, scientific evidence and vernacular experience questions the desirability of wholesale hookworm eradication. There is a concern that the absence of hookworms and other microbes could be as pathological as their excessive presence. Epidemiologists have noted an association between general declines in microbial infection and the increase in susceptibility to certain autoimmune and allergic diseases (Bach, 2002). In 1989 David Strachan offered a 'hygiene hypothesis' to account for these broad trends (Strachan, 1989). This theory has been refined by work that seeks to differentiate the salutary effects of different microbial infections. Immunologists, like Graham Rook (Rook et al., 2014), encourage a separation between harmful 'crowd infections' (which evolved recently because of urbanization) and the microbial 'old friends' with which humans coevolved. 
Rook suggests that radical recent changes in the composition of the human microbiome have led to the loss of the 'old friends mechanism' (Rook, 2009b) through which resident microbiota enable and calibrate vital bodily processes like metabolism, immunity and cognition. The same service is not provided by crowd infections, which either kill the host, or to whom the host develops immunity. While scientific and public health attention remains focused on 'targeted hygiene' and the control of crowd infections (Bloomfield et al., 2016), the salutary effects of the absent venerable human microbiome is emerging as a hot topic in the life sciences.

Hookworms have been identified as one such old friend. The absence of hookworms and other human helminths is currently being afforded significant attention in explaining microbial dysbiosis and its effects on human health. Epidemiological research suggests that 'allergic diseases are rare in areas with high helminth parasite exposure and common where helminth exposure is lacking or significantly reduced, such as urban areas of developing countries and industrialized nations' (Flohr et al., 2009, 20). A long-term observation study of patients with multiple sclerosis infected with different helminths showed that disease activity improved during infection and regressed when infection was treated (Correale and Farez, 2011). Comparable, but by no means clear cut patterns have also been observed for the effects of helminths on diabetes, IBD and metabolic disease (for a review see Wammes et al., 2014).

Immunologists seeking to explain these trends suggest that hookworms produce an entirely different 'immune response profile' to bacterial and viral pathogens (Allen and Maizels, 2011). They argue that because of a long history of human co-evolution, 'helminths have evolved to dampen, rather than disable, the immune system of their hosts' (ibid, 384). Recent work in immunology identifies a 'helminth-induced immune regulatory environment' (Helmby, 2009) through which worms enter into a 'continuing dialogue' (Allen and Maizels, 2011), 385) with the human immune system to enable permanent residence. This work also suggests that in the absence of worms and other components of the microbiome, the immune system becomes poorly calibrated, is unable to differentiate harmful materials, becomes oversensitive, and ultimately turns against itself, resulting in elevated levels of allergy and inflammation (Fleming and Weinstock, 2015). 
Microbiologists use mouse models to trace the complex interactions between the host, helminths and resident bacteria. They suggest that helminths can manipulate the microbial population for their own ends, in ways that explain immune modulation (Reynolds et al., 2015; Zaiss et al., 2015). One set of immunologists has drawn on concepts from conservation biology to explain helminths' calibrating potential (Bilbo et al., 2011). They suggest that hookworms figure as missing 'keystone species': 'species that play a disproportionately large role in the prevalence and population levels of other species within their ecosystem or community' (Wagner, 2010: 51). The past presence of hookworm is sensed as a contemporary absence made manifest in forms of ecosystem dysfunction and 'ecological anachronism' (Barlow, 2013). The concept of ghost keystone species was first developed to explain the 'trophic cascades' caused by the absence of apex predators, like the wolf (Eisenberg, 2010). The absence of these species is understood to tip ecologies into new states characterized by reduced diversity, functionality and resilience. Advocates of helminthic therapy speak of 'Darwinian medicine' (Rook, 2009a) that would address analogous 'evolutionary mismatches' between the ecological composition of human bodies, the immune systems they have trained, and the external environments to which they are exposed (Parker and Ollerton, 2013).

These discussions of the demise of old friends and the causes of the current epidemics of absence implicate practices that are central to the modern, antibiotic approaches to managing microbes that were encountered above (see table one).

\begin{tabular}{|l|l|}
\hline Socio-ecological change & Microbial consequence \\
\hline Clean water & Reduced faecal transmission \\
\hline Increase in caesarean sections & Reduced vaginal transmission \\
\hline Reduced breastfeeding & $\begin{array}{l}\text { Reduced skin-to-skin transmission and a } \\
\text { changed gut flora }\end{array}$ \\
\hline Smaller family size & Reduced early life transmission \\
\hline Widespread antibiotic use & $\begin{array}{l}\text { Reduced vaginal transmission and selection } \\
\text { for a changing composition }\end{array}$ \\
\hline Changing diet and cooking practices & Alterations in gut flora \\
\hline
\end{tabular}




\begin{tabular}{|l|l|}
\hline $\begin{array}{l}\text { Diminished contact with soil and farm } \\
\text { animals }\end{array}$ & Reduced early life transmission \\
\hline $\begin{array}{l}\text { Increased bathing, showering and use } \\
\text { of antibacterial soaps }\end{array}$ & Selection for a changing composition \\
\hline $\begin{array}{l}\text { Increased exposure to 'crowd } \\
\text { infections' }\end{array}$ & Infectious disease \\
\hline
\end{tabular}

Table 1: Table of modern practices understood to negatively affect the human microbiome (taken from Blaser and Falkow, 2009; Bono-Lunn et al., 2016; Rook et al., 2014).

Interventions like flush toilets, antibiotics, and Caesarean sections, that have been central to Western narratives of civilisation and development, have been recast as potentially pathological. We are told that in becoming modern the human microbiome is in danger of unravelling. Immunologists and microbiologists have extended this discussion to pathologise Western urban and post-industrial life. They draw attention to undesirable processes of microbial colonization and the resulting forms of microbiome composition (Hanski et al., 2012; Rook et al., 2014). The story here is of health and safety going too far. An excessive desire to minimize risk and modulate microbial infection intensity creates a model of biosecurity that is prone to autoimmunity: 'a self-protective syndrome whose attempts to exclude difference are ultimately self-destructive' (Hinchliffe and Ward 2014, 143).

Early accounts of inflammatory and autoimmune conditions suggested that these are 'Western diseases' or 'diseases of affluence' (Pollard, 2008), associated with populations that have passed through a spatial epidemiological transition. But there are stark disparities in the socio-economic status of those who currently experience hookworms as a ghost in urban areas around the world (Rook et al 2014). Coping with autoimmune disease may require regimes of immunosuppressant drugs, whose availability is patchy and dependent on an ability to pay. Autoimmune diseases may well be exacerbated by the socio-ecological intensities of urban poverty that generate a perfect microbial storm of absent old friends and amplified exposure to urban crowd infections. The chances of living well without hookworms and other old friends are as strongly configured by entrenched pathologies of power as the situations in which people can live well with worms. 
A figure of hookworms as ghost helps extend Hinchliffe et al's (2016) topological understanding of pathogenicity to explore situations in which microbial absences shift ecological intensities to create dysbiosis. Many of the microbial excesses associated with the emergent infectious diseases of agriculture and urban life may stem from the absence of regulating microbes. But there has been little explicit attention given in medical geography to the topologies of such absences and their effects on autoimmunity. Understanding the immune system legacies of microbial absences requires a more protracted conception of the microbial geographies of health, where the focus is less on the intensities and immediate spatio-temporalities of outbreak (cf Dixon and Jones 2015), and more on intergenerational microbial inheritance, the accumulation of microbial exposure and immunomodulation over the life course, and the cascading effects of microbial absences. Emerging relational geographies of pathogenicity must also attend to the protracted and discordant temporalities of microbial colonization and immune system calibration.

\section{Mutualist}

Anxieties about missing microbes have informed a wide range of laboratory research manipulating the microbiomes of animal models. Experiments and pre-clinical trials with mouse models and murine helminths, comparable to those of humans, try and simulate and explain the links between de- and reworming and the incidence of allergic and autoimmune disease. Wammes et al argue that these experiments in murine helminthic therapy: 'provide strong evidence that helminths can not only downregulate parasite-specific immune responses, but also modulate autoimmune and allergic inflammatory responses and improve metabolic homoeostasis' (2014: 1150).

Human clinical trials of helminthic therapy are now underway. A recent review identifies 28 trials focused on ten different autoimmune diseases, including Crohn's, Multiple Sclerosis and autism (Fleming and Weinstock, 2015). The USA Food and Drug Administration have granted a license to use the ova (eggs) of the pig whipworm Trichuris suis as an investigational medicinal product (Elliott and Weinstock, 2009) and the Danish company Parasite Technologies has patented a production process. In the UK the Medicines and Healthcare Regulatory Authority have licensed the use of Necator americanus (Pritchard, 2011). Trials have 
demonstrated that it is safe to introduce these two species into human patients. But evidence of the efficacy of helminthic therapy has been mixed and inconclusive. Fleming and Weinstock note that 'some phase 2 studies have not achieved positive results for their primary outcome measures' and argue that 'the jury is out as to the efficacy of helminth treatment' (2015: 289) as many studies are in progress, and several were poorly designed. New trials are underway and many more are planned.

In parallel with these clinical developments, and in part in frustration at their slow progress, a variety of patients, citizen scientists and health providers have been reworming. In 2016, there were at least five commercial providers of hookworms and other helminths, all run by people with experience of self-treatment (see Cheng et al., 2015). ${ }^{2}$ Hookworm therapy has been driven by social media, which link together a globally disparate community that operates independently of scientific researchers and commercial providers. Empowered by online resources and their own experiments, some users have learnt to grow their own. They use animals originally purchased from commercial providers, or sourced from participation in clinical trials. Some have cobbled together readily available domestic technologies to make their own laboratories. Detailed incubation protocols circulate containing instructions on how to create surrogate ecologies for incubating and nurturing worms. Making use of cheap microscopes and library images, they harvest and isolate new stock from their faeces and count larvae before self-infecting (for more information see AUTHOR REF).

A recent survey identified 6-7000 'self-treaters', using four different helminth species (Cheng et al 2015). Allergies, IBD and MS were the most common reported conditions. The cost of helminth therapy varies from US\$10 $000->$ US\$1000 per annum, depending on the species used, the dose required and the degree of support provided. This is a marginal economic activity, whose legality is currently unclear. In the main, this 'hookworm underground' involves non-profit, communitarian relations and zealous advocacy. Fellow suffers and users gift or exchange worms at cost. They share experience to ensure reserve supplies and to build capacity. The shared aim of these 'biological citizens' (Rose and Novas, 2008) is to enhance the legitimacy and availability of helminth therapy (cf Epstein, 1996 on patient activism and HIV). 
Here hookworms come to figure as 'symbionts' (Biome Restoration, 2016), 'mutualists' (Pritchard and Brown, 2001) or 'mutualistic symbionts' (Autoimmune Therapies, 2016). Patients talk affectionately of their 'gut buddies', or 'colon comrades' (AUTHOR REF). Mutualism and symbiosis were once synonymous in ecology, but the latter is increasingly used to describe a wider range of relations, including parasitism. Mutualism is more specific and describes a 'relationship existing between two organisms of different species which contribute mutually to each other's well-being' (OED, 2016). In accounting for the mutualistic agencies of hookworms, scientists draw on the accounts of an interspecies dialogue between old friends outlined above. Helminth providers use similar metaphors. They argue that worms initially serve to 'calibrate' a child's immune system before 'exercising' adults' immunity (Biome Restoration, 2016). Worms are understood to 'restore nature's balance' (Autoimmune Therapies, 2016) and enable 'symbiotic immunomodulation' (Symmbio, 2016). They are to be enrolled in a wider project of 'biome restoration' (Biome Restoration, 2016).

We can position this DIY reworming within a broader probiotic turn that is taking place in the management of health in certain Western contexts (AUTHOR REF). Efforts to translate the science of the human microbiome have converged with a reappraisal and reinvention of the microbial dimensions of a range of vernacular cooking and hygiene practices. The result is a range of experiments, interventions and regulations designed to reverse the trends outlined in table 1 (see table 2). Examples would include: the proliferation of pro- and pre-biotic diets and supplements designed to work on the gut microbiome (e.g. Sonnenburg and Sonnenburg, 2015), and private sequencing services to monitor their effects (e.g. uBiome.com); probiotic hygiene products that seed the body or the built environment with good bacteria (e.g. motherdirt.com); and the use of faecal transplants to treat antibiotic resistant infections (Gough et al., 2011) and vaginal seeding to replicate microbial birth canal colonisation in babies born by C-section (Dominguez-Bello et al., 2016).

\begin{tabular}{|l|l|l|}
\hline Socio-ecological change & $\begin{array}{l}\text { Microbial } \\
\text { consequence }\end{array}$ & $\begin{array}{l}\text { Post-Pasteurian management } \\
\text { of microbial intensities }\end{array}$ \\
\hline Clean water & Reduced faecal & Probiotic drinks, like \\
\hline
\end{tabular}




\begin{tabular}{|c|c|c|}
\hline & transmission & Kombucha \\
\hline $\begin{array}{l}\text { Increase in Caesarean } \\
\text { sections }\end{array}$ & $\begin{array}{l}\text { Reduced vaginal } \\
\text { transmission }\end{array}$ & $\begin{array}{l}\text { Discouragement of C-Sections } \\
\text { Swabbing to replicate the } \\
\text { microbial colonization } \\
\text { associated with vaginal } \\
\text { delivery }\end{array}$ \\
\hline Reduced breastfeeding & $\begin{array}{l}\text { Reduced skin-to-skin } \\
\text { transmission and a } \\
\text { changed gut flora }\end{array}$ & $\begin{array}{l}\text { Breast feeding promotion } \\
\text { New types of probiotic and } \\
\text { prebiotic formula }\end{array}$ \\
\hline Smaller family size & $\begin{array}{l}\text { Reduced early life } \\
\text { transmission }\end{array}$ & $\begin{array}{l}\text { Pox parties to spread diseases } \\
\text { like measles and chicken pox* }\end{array}$ \\
\hline Widespread antibiotic use & $\begin{array}{l}\text { Reduced vaginal } \\
\text { transmission and } \\
\text { selection for a } \\
\text { changing composition }\end{array}$ & $\begin{array}{l}\text { Ban on some antimicrobial } \\
\text { cleaning products } \\
\text { Discouraging use of antibiotics } \\
\text { Promotion of probiotics }\end{array}$ \\
\hline $\begin{array}{l}\text { Changing diet and } \\
\text { cooking practices }\end{array}$ & Alterations in gut flora & $\begin{array}{l}\text { Probiotic, raw and paleo diets } \\
\text { Growth in pro- and pre-biotic } \\
\text { dietary supplements }\end{array}$ \\
\hline $\begin{array}{l}\text { Diminished contact with } \\
\text { soil and farm animals }\end{array}$ & $\begin{array}{l}\text { Reduced early life } \\
\text { transmission }\end{array}$ & $\begin{array}{l}\text { Children's 'messy play' and } \\
\text { 'Nature reconnection' projects }\end{array}$ \\
\hline $\begin{array}{l}\text { Increased bathing, } \\
\text { showering and use of } \\
\text { antibacterial soaps }\end{array}$ & $\begin{array}{l}\text { Selection for a } \\
\text { changing composition }\end{array}$ & $\begin{array}{l}\text { Controls on use of } \\
\text { antimicrobials (like Triclosan) } \\
\text { Growth in probiotic hygiene } \\
\text { products and practices }\end{array}$ \\
\hline $\begin{array}{l}\text { Increased exposure to } \\
\text { 'crowd infections' }\end{array}$ & Infectious disease & $\mathrm{n} / \mathrm{a}$ \\
\hline
\end{tabular}

Table 2: Table showing post-Pasteurian responses to modern anxieties about microbial dysbiosis. *Some of these practices shade towards the anti-Pasteurian (Paxson 2014), for example with pox parties organised by anti-vaccination movements.

In these situations, we see hookworms (and other microbes) becoming subject to Paxson's (2008) 'post-Pasteurian' forms of 'microbiopolitics'. Even the most gung-ho advocates of microbial 'rewilding' (e.g. Leach, 2015) are post-, rather than 'anti- 
Pasteurian' (Paxson 2014). Post-Pasteurian reworming is similar to the practices of biosecurity as 'immunity management' documented by Hinchliffe and Ward (2014) in their writings on how pig farmers 'muck-up' sterile animals with earth and faeces to boost their immune systems. But here hookworms are used strategically as a known keystone species to manage the ecological intensities of the bodies into which they are deliberately introduced. Hookworms are deployed to tip dysbiotic bodily ecologies back over the threshold, which triggered autoimmune disease. Like wolves reintroduced to rewild natures reserves, hookworms are enrolled to modulate the intensities of a target ecology and secure desired systemic properties. Hookworms restore immunomodulation and to enhance the resilience of Homo microbis to prevent degenerative change (see AUTHOR REF).

The discovery of hookworms' salutary properties has prompted a range of speculation and research and development on the future of helminth therapy. While advocates speak of restoration and rewilding, there is a growing (and not necessarily incommensurable) desire to gain more control over hookworms and their mutualistic potential. Prominent advocates of helminthic therapy want to persevere with the use of whole organisms. They seek to refine their choice of species and speculate about modifying the helminths currently in use (Elliott et al., 2007; Parker et al., 2012). A very different future is currently being imagined for hookworms by figures in the pharmaceutical industry. Scientists who were involved in decoding the hookworm genome speak of a 'veritable pharmacopoeia' of synthetic molecules that will soon become available for new phases of drug development (Navarro et al., 2013).

On the one hand, there is excitement about new 'drugs from bugs' that will replicate hookworms' abilities to train and calibrate the human immune system (Ditgen et al., 2014). The hope it that the agencies of the hookworm might be simulated in pill form to secure the type of profitable returns currently associated with chronic dependency on immunosuppressant drugs. In this guise the ghostly hookworms return in molecular form to function as the immunological equivalent of a scarecrow: a pared down simulation that mimics a keystone's calibrating agencies.

At the same time, information provided by the hookworm genome and conceptions of helminths in dialogue with microbes, inform a new round of deworming drug and 
vaccine development. New pharmaceuticals might target the bacteria that make the body hospitable to parasitic helminths, reconfiguring the gut microbiome to make it harder for worms to take up residence. Comparable and well-established Global Health programmes to develop a hookworm vaccine (Hotez et al., 2016) are focused on identifying antigens to chemicals secreted at key stages in the hookworm lifecycle. These pharmacological and vaccinological interventions turn the dialogical character of the hookworm, and the embodied history of its human conversation, against the organism (cf Beisel, 2017 on the malaria vaccine). Drugs would exclude hookworms' microbial 'messmates' (Haraway, 2008) and increase its antagonists. While vaccines teach the body to attack on first encounter.

These proposals have been criticized by scientists who point to the cost and the difficulties of recapitulating the ecological agencies of an entire animal in molecular form (Bilbo et al., 2011). They do not believe that a keystone species can be simulated and note that worms will continue to develop drug resistance (Hawdon, 2014). Others have expressed concerns that a successful hookworm vaccine would permanently deprive immunised populations of the immunomodulation benefits of mutualistic infection and increase the risk of dysbiosis amongst already precarious groups (Wammes et al., 2014).

More broadly, critics note the differences between a drug that is designed to treat a specific illness and a live organism that acts preventatively on a bodily ecology to confer health (Bono-Lunn et al., 2016). They suggest that a focus on drugs from bugs ignores the systemic drivers of dysbiosis (Logan et al., 2016). Members of the hookworm underground contest the proprietary tendencies implicit within these developments. They are concerned that profit-centred efforts to privatize the 'hookworm secretome' and eradicate worms may undermine patient-centred benefits already accruing in helminthic therapy. From the perspective of the hookworm, these pharmacological futures can no longer to described as mutualistic. Benefits flow only one way, and the human has become the parasite. Some even hope that new vaccines might enable hookworm eradication.

These post-Pasteurian relations of deliberate re-entanglement with hookworms or their molecular surrogates have quite specific geographies, which are currently under 
explored. Clinical trials in helminthic therapy are focused on populations living near a small number of North American and UK hospitals. The geography of the online hookworm underground is harder to establish. The gatekeepers and most active members of this network on social media, who were contacted in the conduct of this research, are concentrated in North America, Western Europe and Australia. It is likely that mutualistic human-hookworm relations map on to the more affluent regions in which hookworms currently figure as ghosts.

\section{Geography, dysbiosis and Global Health}

This paper has developed a relational geography of the microbiome and of dysbiosis through a focus on disease situations associated with human hookworms. It argues that no microbe is essentially pathogenic; pathogenesis is the outcome of political and ecological relations. The paper adds to existing work on disease situations marked by microbial excesses and offers an analysis of disease situations of microbial absence and proactive restoration. In so doing it identifies three types of human-microbial relation, which are described by the ecological figures of the parasite, ghost and mutualist. The paper maps the global occurrence of each type of relation, their multispecies composition, and their prevalent modes of political economy and forms of microbiopolitics. These are summarised in table three.

\begin{tabular}{|c|c|c|c|}
\hline & Parasite & Ghost & Mutualist \\
\hline Global occurrence & $\begin{array}{l}\text { Tropical areas in the } \\
\text { rural Global South } \\
\text { (figure 3) }\end{array}$ & $\begin{array}{l}\text { Global North and urban } \\
\text { Global South, } \\
\text { especially areas from } \\
\text { which hookworm have } \\
\text { recently been removed. }\end{array}$ & $\begin{array}{l}\text { Poorly mapped. } \\
\text { Scattered across urban } \\
\text { areas of the Global } \\
\text { North. } \\
\text { Some tropical areas in } \\
\text { the Global South with } \\
\text { controlled infection } \\
\text { intensities. }\end{array}$ \\
\hline $\begin{array}{l}\text { Multispecies } \\
\text { composition }\end{array}$ & $\begin{array}{l}\text { Excessive worms, } \\
\text { repeated infection, co- } \\
\text { infection with other } \\
\text { parasites, poor } \\
\text { nutrition, comprised } \\
\text { immune system. }\end{array}$ & $\begin{array}{l}\text { Absent worms. } \\
\text { Dysbiotic microbiome. } \\
\text { Overactive immune } \\
\text { system. }\end{array}$ & $\begin{array}{l}\text { Controlled worm } \\
\text { population, ready } \\
\text { supply of replacement } \\
\text { worms, no inadvertent } \\
\text { infection risk, access to } \\
\text { good nutrition and } \\
\text { managed diet, }\end{array}$ \\
\hline
\end{tabular}




\begin{tabular}{|c|c|c|c|}
\hline & & & immunomodulation. \\
\hline Political Ecology & $\begin{array}{l}\text { Poor sanitation and } \\
\text { healthcare, intensive } \\
\text { plantation agriculture, } \\
\text { poverty and inequality, } \\
\text { limited access to } \\
\text { effective deworming } \\
\text { drugs }\end{array}$ & $\begin{array}{l}\text { Common access to } \\
\text { sanitation, footwear, } \\
\text { deworming drugs and } \\
\text { basic healthcare. } \\
\text { Variable access to } \\
\text { immune-suppressant } \\
\text { drugs. }\end{array}$ & $\begin{array}{l}\text { Wealthy. Good } \\
\text { healthcare and } \\
\text { sanitation. } \\
\text { Worms as common } \\
\text { property with at cost } \\
\text { provision v. growing } \\
\text { private interest in } \\
\text { pharmaceutical } \\
\text { surrogates }\end{array}$ \\
\hline Microbiopolitics & $\begin{array}{l}\text { Pre-Pasteurian, patchy } \\
\text { Pasteurian based on } \\
\text { 'magic bullet' drugs } \\
\text { and vaccines }\end{array}$ & $\begin{array}{l}\text { Antimicrobial. } \\
\text { Involving toilets, } \\
\text { sanitation and national } \\
\text { deworming } \\
\text { programmes }\end{array}$ & $\begin{array}{l}\text { post-Pasteurian in } \\
\text { Urban North involving } \\
\text { controlled } \\
\text { reintroduction by } \\
\text { scientist and expert } \\
\text { patients. } \\
\text { Pre-Pasteurian in rural } \\
\text { Global South with } \\
\text { traditional means of } \\
\text { controlling infection } \\
\text { intensities. }\end{array}$ \\
\hline
\end{tabular}

Table 3: A summary of the key characteristics of the three types of human-microbial relation identified in the paper.

In conclusion, I will briefly reflect upon the implications of this analysis for the geographies of health and for the field of Global Health. But before doing so it is worth reiterating the limitations posed by a focus on hookworms. There are risks in taking hookworms as illustrative of the great diversity of the human microbiome. Hookworms are obligatory animals (i.e. they only reside in humans) that cannot reproduce inside their host. Unlike the bacteria that have been the main focus of recent scientific work on the microbiome, they reproduce slowly and cannot engage in lateral gene transfer. Hookworms' sociability with bacteria and their keystone mutualistic agencies are likely relatively rare. There are plenty of other helminths, let alone viruses and bacteria, with whom such mutualistic relations are improbable (e.g. Moran-Thomas 2013). There are plenty of microbes we might not miss. 
Nonetheless, there are three broad contributions offered by this analysis of humanhookworm relations. First, thinking with hookworms helps open up the radical implications of an ontology of Homo microbis for conceiving the human and human health. These are early days in the development of this science, and much of what is outlined above may well be revised as microbiologists gain more traction on the ecological and immunological dynamics of the human microbiome. But here we are presented with a porous and ecological figure of the human whose life course microbial exposures come to configure identity, subjectivity and health outcomes (cf Meloni, 2015 on epigenetics). Only some of our microbes are inherited and the microbial self is thus open to deliberate or inadvertent modification. This relational ontology of the microbial human challenges how medical geography might conceive space-time. Analysis must focus on life course microbial colonisation, and infection hotspots and vectors. But it must also acknowledge absences and their latent ecological effects (cf Anaya et al., 2016). The human as Homo microbis is an unstable and nonlinear accumulation, marked by disease tipping points with differing degrees of reversibility.

Influential commentators like Donna Haraway (2016), celebrate the ways in which the science of the microbiome and microbial symbiosis offer a post-foundational ontology for more-than-human theory and politics that further undermines Humanist dreams of the bounded individual (see also Hird 2010). Other sociologists of science are more cautious about the new materialisms emerging from the 'microbiomania' (Paxson and Helmreich 2014) of the contemporary biosciences. Drawing together their disparate research on astrobiology and raw milk cheese, Paxson and Helmreich note the ways in which communities of microbes are coming to figure as 'model ecosystems' for a range of hopeful political and ecological projects. They are wary of taking Homo microbis too literally and await its encoding by established power geometries of gendered, racialized and capitalist biotechnology (cf Guthman and Mansfield, 2013 on the coding of environmental epigenetics). While the postgenomic, vital materialism offered by microbiome science can be aligned with the political projects of more-than-human geography, we should be aware of the historical, political and economic conditions that shape its emergence (see Sangodeyi, 2014). The differentiation of microbiome science as it increasingly proliferates across 
the domains of Big Science, biotechnology, citizen science, art-science and DIY biology will be important subjects for future research.

This analysis in this paper begins to lay the foundations for this type of critical work. By identifying the geographies that come to configure the human microbiome, it pluralises Homo microbis, identifying different sub-species of Homo microbi. Tracing how hookworms make and unmake different humans adds to existing criticisms of germ theory and its essentialist understanding of disease as caused by a specific pathogen. Instead this analysis has demonstrated how hookworms, like any other microbe, take on radically different roles in different political-ecological situations. These situations are patterned. They map on to historical and contemporary geographies of colonialism, development, trade, property and urbanisation, to draw out just a few of the processes identified in this story. Hookworms become pathological as parasites in situations of agricultural and industrial intensification and/or political abandonment. The shifting intensities of these situations are familiar from existing work on the emergent diseases of colonialism, agriculture and urbanisation. What this analysis adds is an attention to the pathological potential of microbial absence and the dysbiosis it generates. While the causes of autoimmune and inflammatory disease are multivariate and still unclear, their apparent microbial signature suggests the need for a relational geography of missing microbes. The degree to which the diseases of microbial absence are 'pathologies of power', that can be linked to the structural violence of the unequal provision of healthcare is now an open question. Autoimmune and inflammatory diseases are neglected in medical and health geography and require further research.

Thinking with hookworms helps us begin to answer this question and in so doing to identify some of the implications of the rise of the microbiome for Global Health. While we are some way off knowing what a healthy microbiome looks like - and the answer is unlikely to be singular - there is a growing interest in cultivating the microbiome as a route to individual and public health. Thinking Global Health in terms of the microbiome requires a continued attention to situations of excessive microbial presence, coupled with a new concern for beneficial microbial colonisation and the risks of microbial absence and dysbiosis. Such thinking further complicates linear models of a modern epidemiological transition, in which development can be 
indexed to microbial absence. It suggests a need to recalibrate the discourses inherent (if not explicit) in Global Health that developed countries are healthier because they are cleaner and more devoid of pathogens and microbes, whereas the Global South is the geographic Mecca for bad microbes, dirt, and lack of sanitation. If the pursuit of sterility can be pathological, then Global Health will need to rethink its ontological foundations. $^{3}$

Hookworm control will remain a clear public health priority in many rural areas of the Global South. But it appears that too comprehensive a shift to antibiotic relations with hookworms can instigate autoimmune and inflammatory conditions in populations ill equipped to manage without them. Urban populations with ghostly worms, living in situations with poor sanitation, and exposed to pre-Pasteurian relations with urban crowd infections and novel infectious diseases, are particularly vulnerable to dysbiosis. A concern with contemporary dysbiosis does not necessarily imply an antiPasteurian return to an Eden of universal symbiosis. Pasteurian forms of microbiopolitics have made life better, and their geography is still all too patchy.

Attention turns to a post-Pasteurian recalibration of hygiene that would secure the mutualistic presence of old friends and calculate and manage the intensities of microbial ecologies. This might involve intervening through the strategic use of keystone species to maintain biological diversity and ecosystem functionality. As the story of hookworms makes clear, any panoptic aspiration for a global post-Pasteurian microbiopolitics are confounded by established geographies of underdevelopment. Hookworms illustrate the rarity of situations in which such forms of microbiome management can be achieved. The provision of sanitation, drugs and living organisms is distinctly uneven (cf Braun, 2007). The current focus in Global Health on deworming through vaccination and drug delivery fails to address the socioecological drivers of infection intensity. If these programmes were successful, they risk driving future epidemics of autoimmune disease. In short, the rise of the microbiome raises some profound challenges to the geographies of Global Health whose import has yet to be even realised.

\section{Notes}


${ }^{1}$ See for example the research gathered in The Translational Microbiome Forum www.translationalmicrobiome.org/

${ }^{2}$ For more information on therapeutic helminth providers see: http://wormswell.com, www.autoimmunetherapies.com, https://tanawisa.com, https://biomerestoration.com, and http://www.symmbio.com.

${ }^{3}$ I am grateful to an anonymous reviewer of this paper for the wording of this paragraph.

\section{References}

Ali SH and Keil R (2011) Networked Disease: Emerging Infections in the Global City: Wiley.

Allen J and Maizels R (2011) Diversity and Dialogue in Immunity to Helminths. Nature Reviews Immunology 11(6): 375-388.

Anaya J-M, Ramirez-Santana C, Alzate MA, Molano-Gonzalez $\mathbf{N}$ and RojasVillarraga A (2016) The Autoimmune Ecology. Frontiers in Immunology 7: 139.

Anderson W (2006) Colonial Pathologies: American Tropical Medicine, Race, and Hygiene in the Philippines: Duke University Press.

Anderson W and Mackay I (2014) Intolerant Bodies: A Short History of Autoimmunity: Johns Hopkins University Press.

Autoimmune Therapies (2016) FAQ. Available at: https://autoimmunetherapies.com/

Bach J-F (2002) The Effect of Infections on Susceptibility to Autoimmune and Allergic Diseases. New England Journal of Medicine 347(12): 911-920.

Barlow C (2013) The Ghosts of Evolution: Nonsensical Fruit, Missing Partners, and Other Ecological Anachronisms: Basic Books.

Beisel U (2017) Resistant Bodies, Malaria and the Question of Immunity. In: Herrick C and Reubi D (eds) Global Health and Geographical Imaginaries. London: Routledge, 114-134.

Beisel U and Boëte C (2013) The Flying Public Health Tool: Genetically Modified Mosquitoes and Malaria Control. Science as Culture 22(1): 38-60.

Biome Restoration (2016) The Science. Available at: http://biomerestoration.com/the-science/.

Bilbo S, Wray G, Perkins S and Parker W (2011) Reconstitution of the Human Biome as the Most Reasonable Solution for Epidemics of Allergic and Autoimmune Diseases. Medical Hypotheses 77(4): 494- 04.

Blaser M (2014) Missing Microbes: How Killing Bacteria Creates Modern Plagues: Oneworld Publications.

Blaser M and Falkow S (2009) What Are the Consequences of the Disappearing Human Microbiota? Nat Rev Micro 7(12): 887-894.

Bloomfield SF, Rook GAW, Scott EA, Shanahan F, Stanwell-Smith R and Turner P (2016) Time to Abandon the Hygiene Hypothesis: New Perspectives on Allergic Disease, the Human Microbiome, Infectious Disease Prevention and the Role of Targeted Hygiene. Perspectives in Public Health 136(4): 213-224.

Bono-Lunn D, Villeneuve C, Abdulhay NJ, Harker M and Parker W (2016) Policy and Regulations in Light of the Human Body as a 'Superorganism' Containing Multiple, Intertwined Symbiotic Relationships. Clinical Research and Regulatory Affairs 33(2-4): 39-48.

Braun B (2007) Biopolitics and the Molecularization of Life. Cultural Geographies 14(1): 6-28. 
Braun B (2015) The 2013 Antipode RGS-IBG Lecture New Materialisms and Neoliberal Natures. Antipode 47(1): 1-14.

Brooker S, Bethony J and Hotez P (2004) Human Hookworm Infection in the 21st Century. Advances in Parasitology 58: 197-288.

Brown H and Kelly AH (2014) Material Proximities and Hotspots: Toward an Anthropology of Viral Hemorrhagic Fevers. Medical Anthropology Quarterly 28(2): 280-303.

Brown N and Nettleton S (2017) 'There Is Worse to Come': The Biopolitics of Traumatism in Antimicrobial Resistance (AMR). The Sociological Review Forthcoming.

Brown PJ (1987) Microparasites and Macroparasites. Cultural Anthropology 2(1): 155-171.

Brown TIM and Moon G (2012) Geography and Global Health. The Geographical Journal 178(1): 13-17.

Bull J (2016) Toxic Skin and Animal Mops: Ticks and Humanimal Vulnerabilities. In: Käll LF (ed) Bodies, Boundaries and Vulnerabilities: Interrogating Social, Cultural and Political Aspects of Embodiment. Cham: Springer International Publishing, 81-98.

CDC (2016) Hookworm. Available at: http://www.cdc.gov/parasites/hookworm/.

Cheng A, Jaint D, Thomas S, Wilson J and Parker W (2015) Overcoming Evolutionary Mismatch by Self-Treatment with Helminths: Current Practices and Experience. Journal of Evolutionary Medicine 3: 1-22.

Correale J and Farez MF (2011) The Impact of Parasite Infections on the Course of Multiple Sclerosis. Journal of Neuroimmunology 233(1-2): 6-11.

Couacaud L (2014) Hookworm Disease and Its Relationship to Capitalism and Urban Development. Journal of Political Ecology 21(1): 349-371.

de Silva NR, Brooker S, Hotez PJ, Montresor A, Engels D and Savioli L (2003) Soil-Transmitted Helminth Infections: Updating the Global Picture. Trends in Parasitology 19(12): 547-551.

Ditgen D, Anandarajah E, Meissner K, Brattig N, Wrenger C and Liebau E (2014) Harnessing the Helminth Secretome for Therapeutic Immunomodulators. BioMed Research International 2014.

Dixon DP and Jones JP (2015) The Tactile Topologies of Contagion. Transactions of the Institute of British Geographers 40(2): 223-234.

Dominguez-Bello MG, De Jesus-Laboy KM, Shen N, Cox LM, Amir A, Gonzalez A, Bokulich NA, Song SJ, Hoashi M, Rivera-Vinas JI, Mendez K, Knight R and Clemente JC (2016) Partial Restoration of the Microbiota of CesareanBorn Infants Via Vaginal Microbial Transfer. Nature Medicine 22(3): 250253.

Eisenberg C (2010) The Wolf's Tooth: Keystone Predators, Trophic Cascades, and Biodiversity: Island Press.

Elliott DE, Summers RW and Weinstock JV (2007) Helminths as Governors of Immune-Mediated Inflammation. International Journal for Parasitology 37(5): 457-464.

Elliott DE and Weinstock JV (2009) Helminthic Therapy: Using Worms to Treat Immune-Mediated Disease. In: Fallon PG (ed) Pathogen-Derived Immunomodulatory Molecules. New York, NY: Springer New York, 157-166.

Epstein S (1996) Impure Science: Aids, Activism, and the Politics of Knowledge: University of California Press. 
Ettling J (2013) The Germ of Laziness: Rockefeller Philanthropy and Public Health in the New South: Harvard University Press.

Evans D (2015) Worm Wars: The Anthology. Available at: http://blogs.worldbank.org/impactevaluations/worm-wars-anthology.

Evidence Action (2016) Deworm the World. Available at: http://www.evidenceaction.org/ - deworm-the-world.

Farley J (2003) To Cast out Disease: A History of the International Health Division of Rockefeller Foundation (1913-1951): Oxford University Press, USA.

Farmer P (2004) Pathologies of Power: Health, Human Rights, and the New War on the Poor: University of California Press.

Fleming JO and Weinstock JV (2015) Clinical Trials of Helminth Therapy in Autoimmune Diseases: Rationale and Findings. Parasite Immunology 37(6): 277-292.

Flohr C, Quinnell R and Britton J (2009) Do Helminth Parasites Protect against Atopy and Allergic Disease? Clinical \& Experimental Allergy 39(1): 20-32.

Ginn F, Beisel U and Barua M (2014) Flourishing with Awkward Creatures: Togetherness, Vulnerability, Killing. Environmental Humanities 4: 113-123.

Gough E, Shaikh H and Manges AR (2011) Systematic Review of Intestinal Microbiota Transplantation (Fecal Bacteriotherapy) for Recurrent Clostridium Difficile Infection. Clinical Infectious Diseases 53(10): 994-1002.

Greenhough B (2012) Where Species Meet and Mingle: Endemic Human-Virus Relations, Embodied Communication and More-Than-Human Agency at the Common Cold Unit 1946-90. Cultural Geographies 19(3): 281-301.

Guthman J and Mansfield B (2013) The Implications of Environmental Epigenetics: A New Direction for Geographic Inquiry on Health, Space, and Nature-Society Relations. Progress in Human Geography 37(4): 486-504.

Hanski I, von Hertzen L, Fyhrquist N, Koskinen K, Torppa K, Laatikainen T, Karisola P, Auvinen P, Paulin L, Mäkelä MJ, Vartiainen E, Kosunen TU, Alenius H and Haahtela T (2012) Environmental Biodiversity, Human Microbiota, and Allergy Are Interrelated. Proceedings of the National Academy of Sciences 109(21): 8334-8339.

Haraway DJ (2008) When Species Meet, Minneapolis: University of Minnesota Press.

Haraway DJ (2016) Staying with the Trouble: Making Kin in the Chthulucene: Duke University Press.

Hawdon JM (2014) Controlling Soil-Transmitted Helminths: Time to Think inside the Box? Journal of Parasitology 100(2): 166-188.

Helmby H (2009) Helminths and Our Immune System: Friend or Foe? Parasitology International 58(2): 121-127.

Helmreich S (2009) Alien Ocean : Anthropological Voyages in Microbial Seas, Berkeley: University of California Press.

Helmreich S (2015) Sounding the Limits of Life: Essays in the Anthropology of Biology and Beyond: Princeton University Press.

Herrick C and Reubi D (2017) Global Health and Geographical Imaginaries. London: Routledge.

Hinchliffe S (2015) More Than One World, More Than One Health: Re-Configuring Interspecies Health. Social Science \& Medicine 129: 28-35. 
Hinchliffe S, Allen J, Lavau S, Bingham N and Carter S (2013) Biosecurity and the Topologies of Infected Life: From Borderlines to Borderlands. Transactions of the Institute of British Geographers 38(4): 531-543.

Hinchliffe S, Bingham N, Allen J and Carter S (2016) Pathological Lives: Disease, Space and Biopolitics, London: Blackwell.

Hinchliffe S and Ward KJ (2014) Geographies of Folded Life: How Immunity Reframes Biosecurity. Geoforum 53(0): 136-144.

Hird M (2009) The Origins of Sociable Life: Evolution after Science Studies, Basingstoke: Palgrave Macmillan.

Hotez P (2009) Neglected Diseases Amid Wealth in the United States and Europe. Health Affairs 28(6): 1720-1725.

Hotez P (2013) Forgotten People, Forgotten Diseases: The Neglected Tropical Diseases and Their Impact on Global Health and Development: ASM Press.

Hotez P, Diemert D, Bacon K, Beaumier C, Bethony J, Bottazzi ME, Brooker S, Couto AR, da Silva Freire M, Homma A, Lee B, Loukas A, Loblack M, Morel CM, Oliveira RC and Russell P (2013) The Human Hookworm Vaccine. Vaccine 31, Supplement 2: B227-B232.

Hotez PJ, Beaumier CM, Gillespie PM, Strych U, Hayward T and Bottazzi ME (2016) Advancing a Vaccine to Prevent Hookworm Disease and Anemia. Vaccine 34(26): 3001-3005.

Hotez PJ, Bethony J, Bottazzi ME, Brooker S and Buss P (2005) Hookworm: "The Great Infection of Mankind". PLoS Medicine 2: 0187-0191.

Hotez PJ and Herricks JR (2015) Helminth Elimination in the Pursuit of Sustainable Development Goals: A "Worm Index" for Human Development. PLoS Neglected Tropical Diseases 9(4).

Jahiel RI and Babor TF (2007) Industrial Epidemics, Public Health Advocacy and the Alcohol Industry: Lessons from Other Fields. Addiction 102(9): 13351339.

Kelly AH (2012) The Experimental Hut: Hosting Vectors. Journal of the Royal Anthropological Institute 18(SUPPL. 1).

Koplan JP, Bond TC, Merson MH, Reddy KS, Rodriguez MH, Sewankambo NK and Wasserheit JN (2009) Towards a Common Definition of Global Health. The Lancet 373(9679): 1993-1995.

Latour B (1988) The Pasteurization of France, Cambridge, Mass.: Harvard University Press.

Law J and Mol A (2008) Globalisation in Practice: On the Politics of Boiling Pigswill. Geoforum 39(1): 133-143.

Leach J (2015) Rewild CreateSpace Independent Publishing Platform.

Lezaun J (2011) Bees, Beekeepers, and Bureaucrats: Parasitism and the Politics of Transgenic Life. Environment and Planning D: Society and Space 29(4): 738756.

Logan AC, Jacka FN and Prescott SL (2016) Immune-Microbiota Interactions: Dysbiosis as a Global Health Issue. Current Allergy and Asthma Reports 16(2): 13.

Loon J van (2005) Epidemic Space. Critical Public Health 15(1): 39-52.

Lowe C (2010) Viral Clouds: Becoming H5n1 in Indonesia. Cultural Anthropology 25(4): 625-649. 
Mayer J (2010) Medical Geography. In: Brown T, McLafferty S and Moon G (eds) A Companion to Health and Medical Geography. Oxford: Wiley-Blackwell, 33-54.

Meloni M (2015) Epigenetics for the Social Sciences: Justice, Embodiment, and Inheritance in the Postgenomic Age. New Genetics and Society 34(2): 125151.

Méthot PO and Alizon S (2014) What Is a Pathogen? Toward a Process View of Host-Parasite Interactions. Virulence 5(8): 775-785.

Mitman G (2008) Breathing Space: How Allergies Shape Our Lives and Landscapes: Yale University Press.

Moran-Thomas A (2013) A Salvage Ethnography of the Guinea Worm: Witchcraft, Oracles and Magic in a Disease Eradication Program. In: Biehl J and Petryna A (eds) When People Come First: Critical Studies in Global Health. 207-240.

Mutsaers I (2015) One-Health Approach as Counter-Measure against "Autoimmune" Responses in Biosecurity. Social Science \& Medicine 129: 123-130.

Nading A (2013) Humans, Animals, and Health: From Ecology to Entanglement. Environment and Society: Advances in Research 4(1): 60-78.

Navarro S, Ferreira I and Loukas A (2013) The Hookworm Pharmacopoeia for Inflammatory Diseases. International Journal for Parasitology 43(3-4): 225 231.

OED (2016) Oxford English Dictionary, Oxford: Oxford University Press.

Palmer S (2009) Migrant Clinics and Hookworm Science: Peripheral Origins of International Health, 1840-1920. Bulletin of the History of Medicine 83(4): 676-709.

Palmer S (2010) Launching Global Health: The Caribbean Odyssey of the Rockefeller Foundation: University of Michigan Press.

Parker W and Ollerton J (2013) Evolutionary Biology and Anthropology Suggest Biome Reconstitution as a Necessary Approach toward Dealing with Immune Disorders. Evolution, Medicine, and Public Health 2013(1): 89-103.

Parker W, Perkins SE, Harker M and Muehlenbein MP (2012) A Prescription for Clinical Immunology: The Pills Are Available and Ready for Testing. A Review. Current Medical Research and Opinion 28(7): 1193-1202.

Paxson H (2008) Post-Pasteurian Cultures: The Microbiopolitics of Raw-Milk Cheese in the United States. Cultural Anthropology 23(1): 15-47.

Paxson H (2014) Microbiopolitics. In: Kirksey E (ed) The Multispecies Salon. Durham: Duke University Press, 115-121.

Paxson H and Helmreich S (2014) The Perils and Promises of Microbial Abundance: Novel Natures and Model Ecosystems, from Artisanal Cheese to Alien Seas. Social Studies of Science 44(2): 165-193.

Pollard TM (2008) Western Diseases: An Evolutionary Perspective: Cambridge University Press.

Porter N (2013) Bird Flu Biopower: Strategies for Multispecies Coexistence in Việt Nam. American Ethnologist 40(1): 132-148.

Pritchard D (2011) Worm Therapy: For or Against? Journal of Helminthology 85(3): 225-227.

Pritchard DI and Brown A (2001) Is Necator Americanus Approaching a Mutualistic Symbiotic Relationship with Humans? Trends in Parasitology 17(4): 169-172. 
Pullan RL and Brooker SJ (2012) The Global Limits and Population at Risk of SoilTransmitted Helminth Infections in 2010. Parasites and Vectors 5(1).

Relman DA (2015) The Human Microbiome and the Future Practice of Medicine. JAMA 314(11): 1127-1128.

Reynolds LA, Finlay BB and Maizels RM (2015) Cohabitation in the Intestine: Interactions among Helminth Parasites, Bacterial Microbiota, and Host Immunity. The Journal of Immunology 195(9): 4059-4066.

Rook G (2009a) The Hygiene Hypothesis and Darwinian Medicine: Birkhäuser Basel.

Rook G (2009b) Review Series on Helminths, Immune Modulation and the Hygiene Hypothesis: The Broader Implications of the Hygiene Hypothesis. Immunology 126(1): 3-11.

Rook GAW, Raison CL and Lowry CA (2014) Microbial 'Old Friends', Immunoregulation and Socioeconomic Status. Clinical and Experimental Immunology 177(1): 1-12.

Rose N and Novas C (2008) Biological Citizenship. Global Assemblages. Oxford: Blackwell 439-463.

Sangodeyi FI (2014) The Making of the Microbial Body, 1900s-2012. History of Science. Cambridge: Harvard.

Serres M (2007) The Parasite, Minneapolis: University of Minnesota Press.

Shukin N (2009) Animal Capital : Rendering Life in Biopolitical Times, Minneapolis: University of Minnesota Press.

Singer M (2010) Ecosyndemics: Global Warming and the Coming Plagues of the Twenty-First Century. In: Herring DA and Swedlund AC (eds) Plagues and Epidemics: Infected Spaces Past and Present. Oxford: Berg, 21-38.

Sonnenburg J and Sonnenburg E (2015) The Good Gut: Taking Control of Your Weight, Your Mood, and Your Long-Term Health: Penguin Publishing Group.

Strachan D (1989) Hay Fever, Hygiene, and Household Size. BMJ 299(6710): 12591260.

Symmbio (2016) About Us. Available at: www.symmbio.com/about-us/.

Velasquez-Manoff M (2012) An Epidemic of Absence: A New Way of Understanding Allergies and Autoimmune Diseases: Scribner.

Wagner S (2010) Keystone Species. Nature Education Knowledge 3: 51.

Wallace R and Wallace RG (2015) Blowback: New Formal Perspectives on Agriculturally Driven Pathogen Evolution and Spread. Epidemiology and Infection 143(10): 2068-2080.

Wallace RG (2009) Breeding Influenza: The Political Virology of Offshore Farming. Antipode 41(5): 916-9 1.

Wammes L, Mpairwe H, Elliott A and Yazdanbakhsh M (2014) Helminth Therapy or Elimination: Epidemiological, Immunological, and Clinical Considerations. The Lancet Infectious Diseases 14(11): 1150-1162.

WHO (2016) Intestinal Worms: Strategy. Available at: http://www.who.int/intestinal_worms/strategy/en/.

Wolfe ND, Dunavan CP and Diamond J (2007) Origins of Major Human Infectious Diseases. Nature 447(7142): 279-283.

Zaiss M, Rapin A, Lebon L, Dubey Lalit K, Mosconi I, Sarter K, Piersigilli A, Menin L, Walker Alan W, Rougemont J, Paerewijck O, Geldhof P, McCoy K D, Macpherson A J, Croese J, Giacomin PR, Loukas A, Junt T, Marsland B J and Harris N L (2015) The Intestinal Microbiota Contributes 
to the Ability of Helminths to Modulate Allergic Inflammation. Immunity 43(5): 998-1010. 


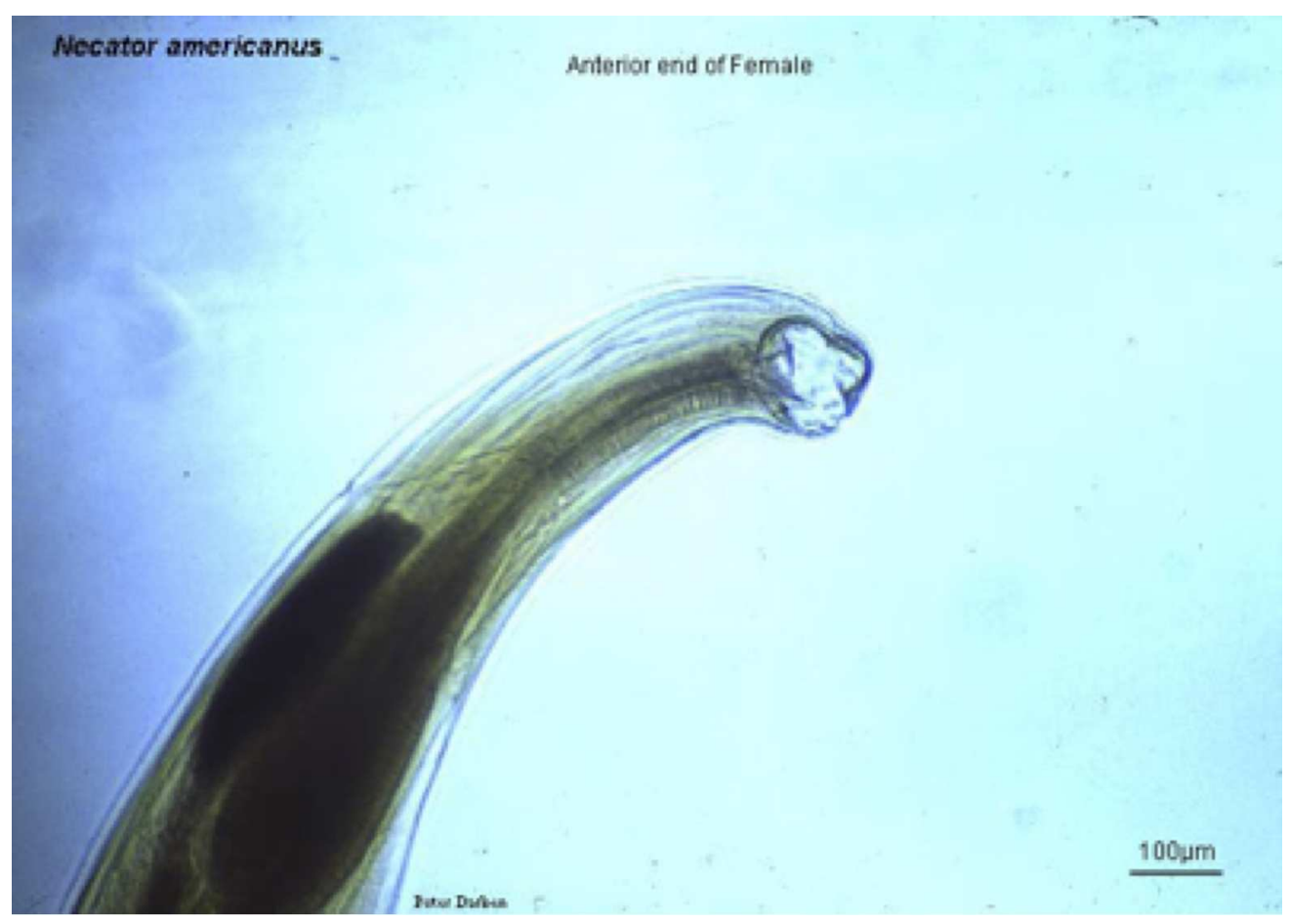

Figure 1: Necator americanus (Source CDC)

$140 \times 99 m m(300 \times 300$ DPI) 

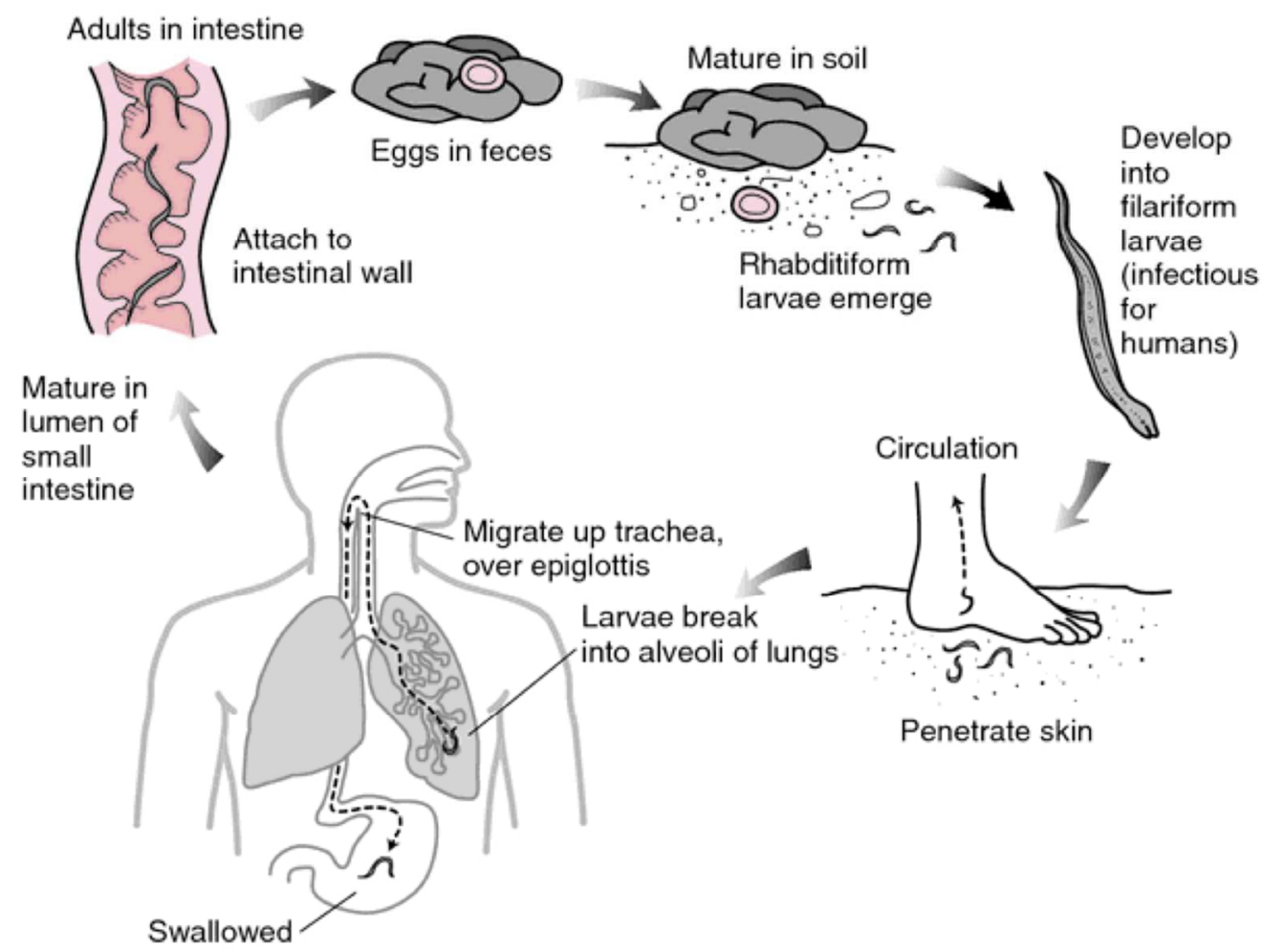

Figure 2: Necator americanus lifecycle (Sourrce: CDC) $212 \times 161 \mathrm{~mm}(150 \times 150 \mathrm{DPI})$ 


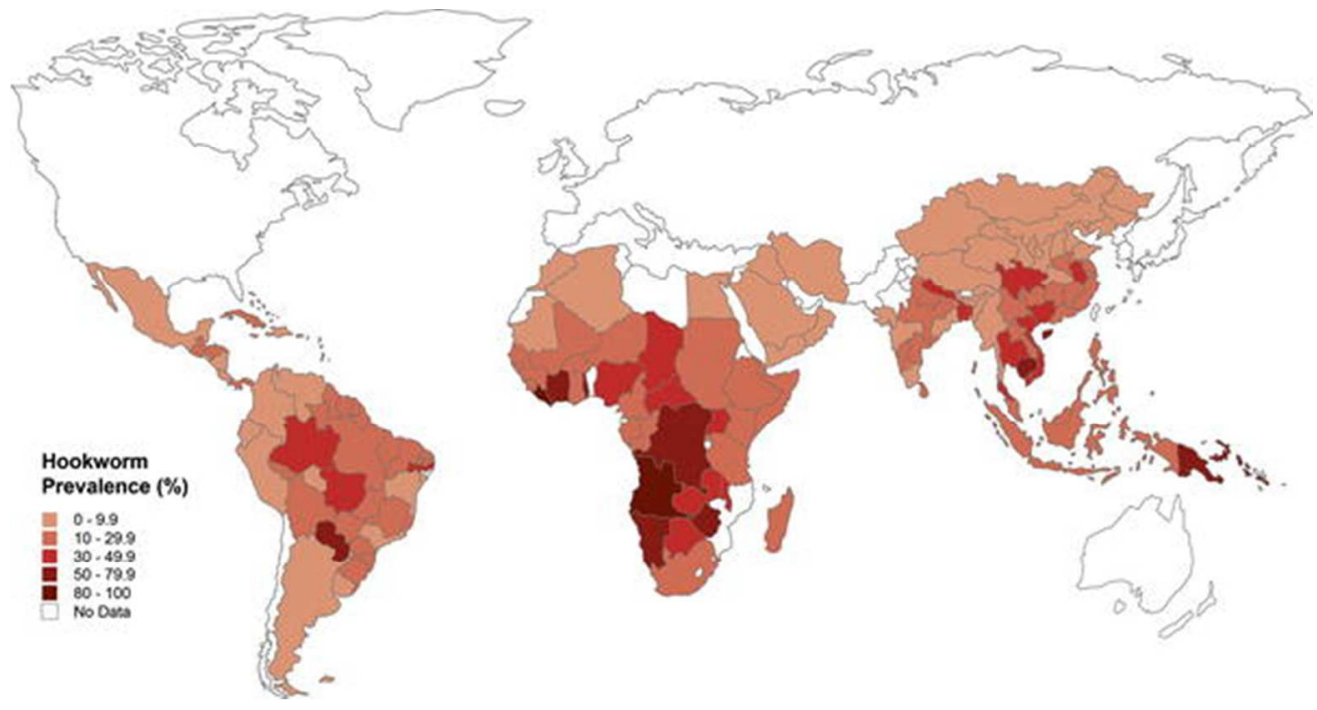

Global distribution of Necator Americanus in 2003 (from de Silva 2003)

$211 \times 112 \mathrm{~mm}(72 \times 72 \mathrm{DPI})$ 